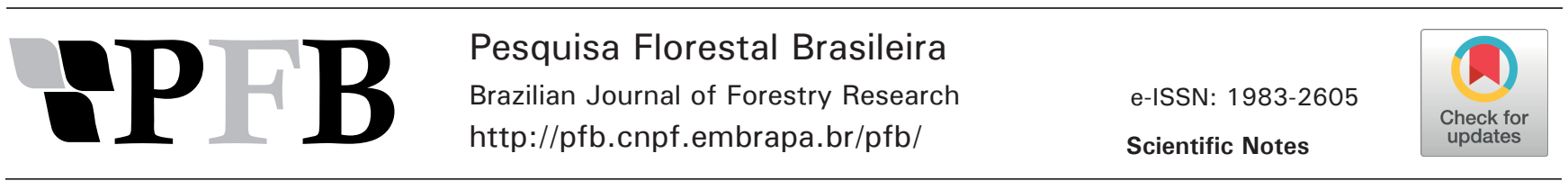

\title{
Validation of an automatic evaluation of sticky traps for fungus-gnats
}

\author{
Guilherme Schnell e Schühli ${ }^{*}(\mathbb{D})$, Pedro Cazetta da Cruz $^{2}$ (D), Luziane Franciscon ${ }^{1}$ (D), Edilson Batista de Oliveira ${ }^{1}$ (D) \\ ${ }^{1}$ Embrapa Florestas, Estrada da Ribeira, km 111, CP. 319, CEP: 83411-000, Colombo, PR, Brazil \\ ${ }^{2}$ Pontifícia Universidade Católica do Paraná, Rua Imaculada Conceição, 1155, Prado Velho, CEP 80215-901, Curitiba, PR, Brazil
}

"Corresponding author:

guilherme.schuhli@embrapa.br

Index terms:

Sciaridae

Insect sampling

Automation

Termos para indexação:

Sciaridae

Amostragem de insetos

Automatização

Received in 20/11/2018

Accepted in 26/11/2018

Published in 20/12/2019

cc) $(1) \Theta$

\begin{abstract}
The evaluation of adhesive trap is a time-consuming task, vulnerable to count errors. Our proposition originated from the need to perform periodical evaluations of fungus-gnats (Diptera: Sciaridae). We selected, at random, 100 traps samples from a single site. Manual counting was performed and the traps were subsequently submitted to digitalization and automatic counting. We perform comparisons of both counting methods using $\mathrm{R}$. The proposed automatic based approach is more expeditious in analyzing bigger samples or in including larger areas.
\end{abstract}

\section{Validação de contagem automática de insetos em armadilhas adesivas amarelas para fungus-gnats}

\begin{abstract}
Resumo - A avaliação de insetos pragas por armadilhas adesivas é uma tarefa demorada, sujeita a erros de contagem. Nossa proposição originou-se da necessidade de realizar avaliações periódicas de infestações de mosquitos (Diptera: Sciaridae). Foram selecionadas 100 armadilhas, em um único local. A contagem manual foi realizada e as armadilhas foram posteriormente submetidas à digitalização e contagem automática. O programa $\mathrm{R}$ foi utilizado para comparação entre os métodos de contagem considerados. A abordagem automática sugerida, quando comparada à tradicional, permite esforços de amostragem mais rápidos, maiores coleções de registros de dados ou ainda maiores áreas amostradas em menos tempo.
\end{abstract}

Several alternatives to capture insects are available. Some strategies are relevant to qualitatively document the species while others are used for quantitative assessment. The adhesive traps (AT) also known as "sticky" traps, were developed originally for collecting Homoptera (Juillet, 1963) but turned to be widely used for trapping small winged insects, mainly agricultural pests (Muirhead-Thomson, 1991). The AT uses a simple glue coat over a cardboard capturing insects which alight or fly on to them or even are blown against them by the wind (Johnson, 1950).
The use of the AT offers many advantages as the maintenance of the physical evidence in collections of traps as vouchers. The traps are easily installed and may even be posted by mail to taxonomic identification. These traps are commonly used not only for assessments but also largely employed as population control devices (Muirhead-Thomson, 1991).

Nonetheless, the quantitative record in this type of trap, for example as used by Johnson (1950) for population density studies, is a time-consuming task, vulnerable to count errors and subjectivity. 
Schühli (2013) suggested that this difficulty could be overcome by trivial computational procedures already available in image analysis programs. The same author mentioned that image analysis software such as the ImageJ (Rueden et al., 2017) could perform this counting since the program was already known to perform similar tasks in the biological sciences approaches. Our proposition originated from our own necessity to evaluate populations of swarms of fungusgnats (Diptera: Sciaridae) on infested log piles in panels industries (Schühli et al., 2014; Amorim \& Schühli, 2017). The insect becomes a severe nuisance and control measures are necessary. Many species were identified (as Euricrium varians, and Bradysisa matogrossensis) and even described (Euricrium edwardsii) (Amorim \& Schühli, 2017).

As a proof of concept, we processed the traditional visual count of a mixed environmental sample. The results were compared to a computational count. The software should differentiate captures to recognize and count only the sciarid.

Adhesive yellow traps measuring 11 by $25 \mathrm{~cm}$ were used (Biocontrole $\AA$ ). Samples were collected in a single location $(-26.089831,-49.425472)$ were swarms of Sciaridae were reported as a nuisance pest. Traps were installed at $1.5 \mathrm{~m}$ high and exposed from $11 \mathrm{~h}$ to $13 \mathrm{~h}$. We limited the exposure time to a standard to minimize overlapping captures. The daytime was chosen to fit the operational schedule of the company. The sampling was repeated every 15 days on two locations inside the $\log$ yard with 15 traps per spot. After the exposition, we covered the traps with transparent polypropylene plastic film. Date, location, climatic conditions, time of exposition and collector were registered in a label on the trap outside the adhesive area.

From our sampled traps, we selected, at random, 50 AT. Manual counting was performed on each side of the traps registering the result in a separated list. The traps were subsequently submitted to digitalization. Traps were positioned on a table perpendicularly to the camera. A piece of common glass was used to flatten the trap and therefore to prevent parallax errors. Traps were digitalized both sides including their original label. Image acquisition was done in a Canon EOS 1100D SLR (4.2 K x $2.8 \mathrm{~K}$ pixels, 72 x 72 dpi, 24 bits, RGB). The camera was fixed $(18 \mathrm{~mm})$ in a stand and remotely shot trough DigicamControl - Free Windows DSLR camera controlling solution (Duka, 2015).
We followed the recommendations from the protocol illustrated in Schühli (2013):

a) a picture/scan was produced in full color;

b) a scale was computed based on one of the known dimensions of the trap;

c) the image was cropped to contain exclusively the trap area;

d) the image was transformed reducing the file to an 8 or 16 bits image file;

e) the threshold value was informed;

f) the size range was informed and the particles were counted and summarized.

Traditional error measures were calculated in $\mathrm{R}$ software to comparisons of both counting methods. The mean percentage error (MPE) is the computed average of percentage errors by which forecasts if a model differs from actual values of the quantity being forecast. The mean absolute scaled error (MASE) is a measure of the accuracy of forecasts and represents a generally applicable measure of forecast accuracy.

A pilot experiment was performed to adjust the sciarid recognition. To calibrate the recognition under our specific conditions we adjusted the size of recognition to our known size range (by calculating the average radius and radius variance within 1.000 insects). Also, we performed a brief evaluation to obtain optimal threshold values. We evaluated 20 random samples within our optimal range (counted automatically with four threshold values $80,85,90$, and $95 \%$ ) comparing with their manual counting values. Smallest error measures (MPE and MAPE) within this range was used to process the whole sample.

A simple plot to illustrate both measures was constructed in $\mathrm{R}$. A regression and $95 \%$ confidence interval was plotted. Outliers were re-visited to verify where the error occurred. As the electronic procedure pinpoint each count it was possible to confront whether it was an error of manual counting or a misinterpretation of the image processing.

We gathered 100 sampled surfaces varying from 20 to 308 captured insects. The average capture was 103 insects per surface $($ Median $=99.5$; standard deviation $(\mathrm{sd})=53.3)$.

Our pilot experiment to define recognition suggested a radius value within $1-10 \mathrm{~mm}$. Prior threshold test at 80 , 85,90 and 95 returned respectively 13.6, 8.3, 53.2 and $132 \%$ as MPE and also to MASE (except at 85 where MASE returned $8.9 \%$ ). 
Whole sample counting with threshold 85 returned $4 \%$ of MPE and $5.9 \%$ MASE.

Both counting methods illustrating the reading error of the automatic procedure may be compared at Figure 1. Comparisons of outliers showed that imaging capture and transformation can sometimes generate artifacts mainly when captured insects are overlapped. If we trace an absolute correspondence line it is possible to suggest that the procedure tends to slightly overestimate counts in captures (near 80 insects) or underestimate (over 175 insects).

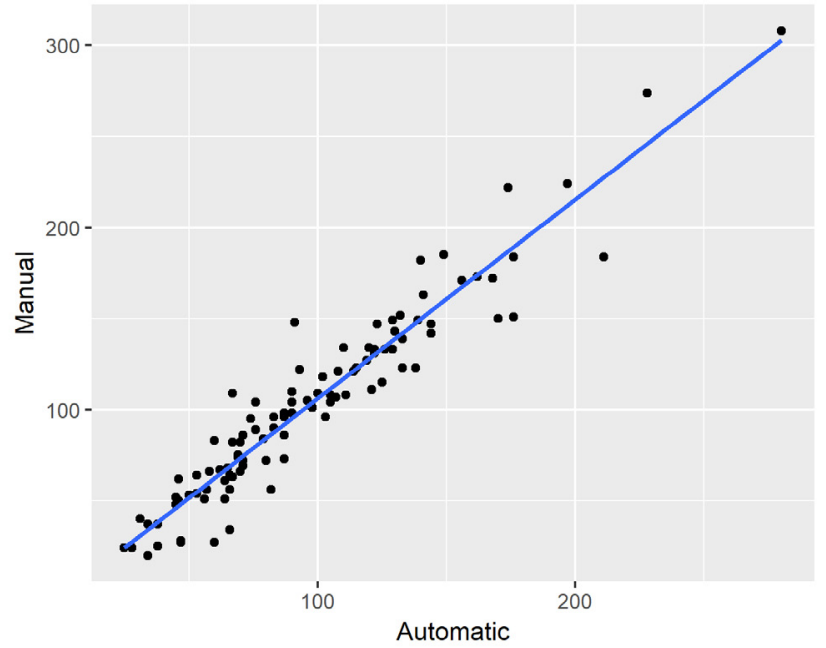

Figure 1. Automatic (x) and manual (y) counts of captured insects in adhesive traps, automatic counts resulted in an error measure (MPE/MASE) lower than $6 \%$ when compared to manual counts.

The method was able to recover values within $4 \%$ (MPE) or $6 \%$ (MASE) of error. Certainly this margin should be evaluated in each intended scenario. Nonetheless this margin is quite reasonable considering the fast and easy processing of the automatic method. During previous automated insect counting efforts as, for example, Arbogast et al. (2000), a mean absolute value of error of $31.7 \%$ was reached.

The gain in processing time by automatic counting largely overpasses the low error measures. Since it is very difficult to generalize the manual counting skills under so many variables we illustrate that three different analyzers take more than $4 \mathrm{~h}$ each to count and record all the AT while the automatic processing of the same AT took less than $2 \mathrm{~h}$ (including the time to acquire the images).

Better results demands trap with minimal overlapped or joined insects. Traps with long exposition could "overflow" with successive captures confusing the reading. We consider that these slight under and overestimation within the tested range wouldn't affect the benefits of the feasible large datasets based on our method. One should consider that manual counting is also subject to the same effects of errors of over or under exposition due to sample overlapping, artifacts or undesirable captures.

Trapped particles within the specified insect size range clearly interfere with the automatic counting. This interference may be noted in the slight differences in moments of over/underestimation. This noise may be still proper for many researches where the methodology doesn't depend on high accuracy. The effect may be important when establishing sampling time and capture saturation in further projects. One should observe the optimal trap sampling in such a way to avoid spurious interference of objects (other species, and artifacts like dirt or wood debris) within the same size range.

\section{Conclusion}

Automation in insect capture analysis is possible with simple digital image processing tools. The error is quite acceptable facing the fast processing and execution time when compared to the manual or traditional counting. Here we demonstrated a valuable tool to save time and use discrete objective criteria in evaluations (as diameter range, for example). The discrimination power was able in our test to recognize the main object from other taxa (under taxonomic family level). This automatic counting technique would allow the feasibility of surveys that require extensive sampling but have little time for sample evaluation. Therefore it seems reasonable to apply these procedures in further sampling approaches allowing costs saving and obtaining bigger data-sets.

\section{Aknowledgements}

We thank Fundação Araucária (PR/Brazil) for the internship of the undergraduate academic student (Bsc) Pedro Cazetta da Cruz (Pontifícia Universidade Católica do Paraná - PUCPR); and also Fundo Nacional de Controle de Pragas Florestais - FUNCEMA (PR/ Brazil) for founding this research (SEG Embrapa 03.17.00.081.00.00, Contrato de cooperação técnica 21500.17/0036-6 Embrapa FUNCEMA). 


\section{References}

Amorim, D. de S. \& Schühli, G. S. A new species of Euricrium Enderlein from southern Brazil, new records for E. varians (Lane), a new combination, and a key for the Neotropical species of the genus. Zootaxa, v. 4231, n. 3, p. 327-340, 2017. https://doi.org/10.11646/ zootaxa.4231.3.2.

Arbogast, R. T. et al. Insect infestation of stored oats in Florida and field evaluation of a device for counting insects electronically. Journal of Economic Entomology, v. 93, n. 3, p. 1035-1044, 2000. https://doi.org/10.1603/0022-0493-93.3.1035.

Duka, I. DigicamControl: free Windows DSLR camera controlling solution. 2015. Avaliable from: < http://digicamcontrol.com/>. Access on: 11 dez. 2015.

Johnson, C. G. The comparison of suction trap, sticky trap and net for the quantitative sampling of small airborne insects. Annals of Applied Biology, v. 37, n. 2, p. 268-285. 1950. https://doi. org/10.1111/j.1744-7348.1950.tb01045.x.
Juillet, J. A. A comparison of four types of traps used for capturing flying insects. Canadian Journal of Zoology, v. 41, p. 219-223. 1963. https://doi.org/10.1139/z63-023.

Muirhead-Thomson, R. C. Flight traps and interceptor traps. I, in: Muirhead-Thomson, R. C. (Ed.). Trap responses of flying insects. San Diego, CA: Academic Press, 1991, p. 152-179. https://doi. org/10.1016/B978-0-12-509755-0.50009-8.

Rueden, C. T. et al. ImageJ2: ImageJ for the next generation of scientific image data. BMC Bioinformatics, v. 18, n. 1, p. 1-26, 2017. https://doi.org/10.1186/s12859-017-1934-z.

Schühli, G. S. Contagem automática de insetos em armadilhas adesivas: uma sugestão baseada no monitoramento de Sciaridae. Colombo: Embrapa Florestas, 2013. 7 p. (Embrapa Florestas. Comunicado técnico, 330). Disponível em: $<$ https://www.infoteca. cnptia.embrapa.br/infoteca/handle/doc/976873>.

Schühli, G. S et al. Sciarid fungus-gnats as nuisance factor in Pinus timber yards. Pesquisa Florestal Brasileira, v. 34, n. 80, p. 1-3, 2014. https://doi.org/10.4336/2014.pfb.34.80.732. 